\title{
Cross-sectional and longitudinal characterization of SCD patients recruited from the community versus from a memory clinic: subjective cognitive decline, psychoaffective factors, cognitive performances, and atrophy progression over time
}

Elizabeth Kuhn ${ }^{1 \dagger}$, Inès Moulinet ${ }^{1 \dagger}$, Audrey Perrotin ${ }^{1}$, Renaud La Joie ${ }^{2}$, Brigitte Landeau ${ }^{1}$, Clémence Tomadesso ${ }^{1,3}$, Alexandre Bejanin ${ }^{1}$, Siya Sherif ${ }^{1}$, Vincent De La Sayette ${ }^{3,4}$, Béatrice Desgranges ${ }^{3}$, Denis Vivien ${ }^{1,5}$, Géraldine Poisnel ${ }^{1}$ and Gaëlle Chételat ${ }^{1 *}$ (i)

\begin{abstract}
Background: Subjective cognitive decline (SCD) defines a heterogeneous population, part of which having Alzheimer's disease (AD). We aimed at characterizing SCD populations according to whether or not they referred to a memory clinic, by assessing the factors associated with increased AD risk.

Methods: Seventy-eight cognitively unimpaired older adults from the IMAP+ study (Caen) were included, amongst which 28 healthy controls (HC) and 50 SCD recruited from the community (SCD-community; $n=23$ ) or from a memory clinic (SCD-clinic; $n=27$ ). Participants underwent cognitive, psychoaffective, structural MRI, FDG-PET, and amyloid-PET assessments. They were followed up over a mean period of $2.4 \pm 0.8$ years. The groups were compared in terms of baseline and follow-up levels of SCD (self- and informant-reported), cognition, subclinical anxiety and depression, and atrophy progression over time. We also investigated SCD substrates within each SCD group through the correlations between self-reported SCD and other psychometric and brain measures.

Results: Compared to HC, both SCD groups showed similar cognitive performances but higher informant-reported SCD and anxiety. Compared to SCD-community, SCD-clinic showed higher informant-reported SCD, depression score, and atrophy progression over time but similar brain amyloid load. A significant increase over time was found for depression in the SCD-community and for self-reported praxis-domestic activities SCD factor in the SCD-clinic. Higher self-reported SCD correlated with (i) lower grey matter volume and higher anxiety in SCD-community, (ii) greater informant-reported SCD in SCD-clinic, and (iii) lower glucose metabolism in both SCD groups.

(Continued on next page)
\end{abstract}

\footnotetext{
* Correspondence: chetelat@cyceron.fr

${ }^{\dagger}$ Elizabeth Kuhn and Inès Moulinet contributed equally as the first authors.

'Inserm, Inserm UMR-S U1237, GIP Cyceron, Université de Caen-Normandie,

Boulevard H. Becquerel, 14000 Caen, France

Full list of author information is available at the end of the article
}

(c) The Author(s). 2019 Open Access This article is distributed under the terms of the Creative Commons Attribution 4.0 International License (http://creativecommons.org/licenses/by/4.0/), which permits unrestricted use, distribution, and reproduction in any medium, provided you give appropriate credit to the original author(s) and the source, provide a link to the Creative Commons license, and indicate if changes were made. The Creative Commons Public Domain Dedication waiver (http://creativecommons.org/publicdomain/zero/1.0/) applies to the data made available in this article, unless otherwise stated. 


\begin{abstract}
(Continued from previous page)
Conclusions: Higher subclinical depression and informant-reported SCD specifically characterize the SCD group that refers to a memory clinic. The same group appears as a frailer population than SCD-community as they show greater atrophy progression over time. Yet, both the SCD groups were quite similar otherwise including for brain amyloid load and the SCD-community showed increased depression score over time. Altogether, our findings highlight the relevance of assessing psychoaffective factors and informant-reported SCD in SCD populations and point to both differences and similarities in SCD populations referring or not to a memory clinic.
\end{abstract}

Keywords: Neuroimaging, Biomarkers, Pathological ageing, Preclinical Alzheimer's disease, Psychoaffective factors, Subjective cognitive decline

\section{Background}

Subjective cognitive decline (SCD) refers to individuals' perceived decline in memory and/or other cognitive abilities relative to their previous level of performance, in the absence of objective neuropsychological deficits [1]. Although these individuals have been described for decades [2], they have received increasing attention over the past few years due to growing interest in characterizing the preclinical stages of Alzheimer's disease (AD) [3, 4]. Recent cross-sectional studies have shown that SCD is associated with neuroimaging biomarkers suggestive of $A D$ such as hippocampal/parahippocampal atrophy [5-17] and/or temporoparietal hypometabolism $[5,18,19]$, and cortical amyloid $\beta$ (A $\beta$ ) deposition [18, 20-24] (see [25] for review). Longitudinal investigations have repeatedly shown that SCD is also associated with an increased risk of subsequent cognitive decline $[26,27]$ or conversion to mild cognitive impairment (MCI) or AD dementia [28-34]. There is thus converging evidence that $\mathrm{SCD}$ is associated with an increased risk of $\mathrm{AD}$ dementia and might represent, at least for some cases, the first clinically observable sign of Alzheimer's clinical syndrome [35].

However, the links between SCD and AD biomarkers have not been reported in all studies (see [25] for review), which might reflect the fact that SCD is multidetermined. Thus, SCD may be due to AD but also non$\mathrm{AD}$ aetiologies (see [36] for review, [37]) including normal ageing [38], poor general health [38, 39], medication [1], sleep disorders [40-43], or psychoaffective factors such as anxiety and depression [39-41, 44]. The current challenge, as highlighted in an international collaborative working group on SCD called the SCD-Initiative (SCD-I; $[1,45]$ ), is thus to identify the specific characteristics of SCD that are associated with an increased likelihood of AD aetiology [1, 45].

An important source of heterogeneity in the definition and aetiology of SCD patients is their type of recruitment [25] (see [46-48] for review). Indeed, typical research settings include population-based studies [6, 24], volunteer samples $[18,20,21,23]$, and/or medical helpseeking samples [5, 7-12, 22]. In a previous study [25], we showed that SCD patients who refer to a memory clinic, referred to as SCD-clinic, had significant atrophy in $\mathrm{AD}$-sensitive regions compared to $\mathrm{SCD}$ individuals recruited from a self-reported SCD questionnaire in volunteers from the community, referred to as SCD-community in what follows. This previous study suggested that SCDclinic as a group is further along the Alzheimer's clinical syndrome trajectory than SCD-community.

In this study, our aim was to provide further evidence towards this statement with a more complete characterization of both SCD-clinic and SCD-community populations of the substrates of their SCD and of their evolution.

For this purpose, we first highlighted the similarities and differences between the two SCD populations in terms of cognitive performances, psychoaffective measures, informant-reported SCD, and the type of selfreported SCD. Informant-reported SCD is recognized as a feature that influences the likelihood of preclinical $\mathrm{AD} /$ Alzheimer's syndrome-confirmation of cognitive decline by an informant being associated with increased risk for preclinical AD/Alzheimer's syndrome $[1,45,49,50]$. Moreover, subclinical symptoms of anxiety or depression might be related with SCD and may constitute risk factors for subsequent cognitive decline and/or be early manifestations of preclinical Alzheimer's syndrome [51-55]. In addition, a previous study showed that SCD of different cognitive domains were differentially associated with preclinical Alzheimer's syndrome [56].

Second, we investigated the substrates of self-reported SCD within each SCD group by assessing the correlations with informant-reported SCD, psychoaffective and cognitive measures, and neuroimaging biomarkers (grey matter atrophy, cerebral glucose hypometabolism, and amyloid deposition).

Finally, we studied the evolution of the groups over a mean follow-up period of 2.4 years in terms of SCD, psychoaffective and cognitive measures, and atrophy progression over time. We also assessed how baseline variables predicted subsequent cognitive decline. 


\section{Methods}

\section{Subjects}

A total of 78 cognitively unimpaired individuals were included from the Imagerie Multimodale de la maladie d'Alzheimer à un stade Précoce (IMAP+) study (Caen, France). The inclusion and exclusion criteria are detailed in previous publications. Briefly, participants were all aged over 50 years; had at least 7 years of education; had no history of alcoholism, drug abuse, head trauma, or psychiatric disorder; and performed in the normal range on a standardized neuropsychological examination $[8,25,57]$.

Participants were recruited from two main sources, memory clinic or public advertising (see Fig. 1). The first group of SCD patients was recruited from a local memory clinic consultation (SCD-clinic) that they attended because of memory concerns. The clinical diagnosis was obtained by a multidisciplinary consensus under the supervision of a senior neurologist. The subjective cognitive decline was self-reported to the clinician during the interview and with a 10-item SCD questionnaire, the Cognitive Complaint Questionnaire [58]. Before inclusion, the clinician checked that the SCD was not caused by medication, psychoaffective conditions (including a major depressive disorder or generalized anxiety disorder), or other medical conditions. Amongst the 41 patients who met these criteria, only those for which the main variables of interest (self- and informant-reported SCD questionnaires and objective episodic memory score) were available were included in the present study, resulting in a group of $27 \mathrm{SCD}$-clinic.

Fifty-one participants were recruited from the community through public advertising, as they volunteered to

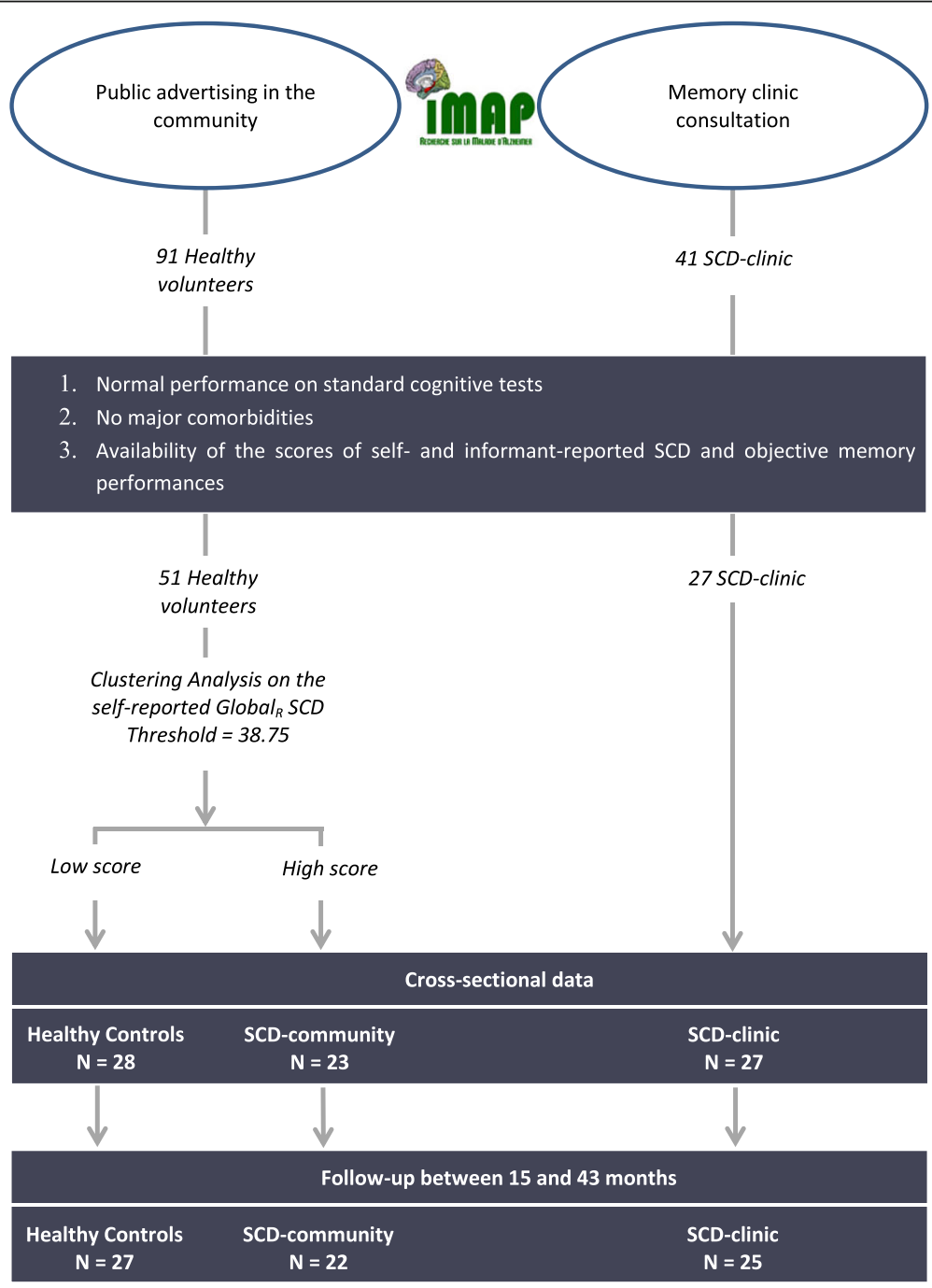

Fig. 1 A flow chart of participant selection and categorization. The graphic shows the steps to select the participants finally included in the three groups of interest of the present study - the healthy controls and the cognitively unimpaired older adults with subjective cognitive decline (SCD) who referred (SCD-clinic) or not (SCD-community) to a memory clinic. All participants were selected from the Imagerie Multimodale de la maladie d'Alzheimer à un stade Précoce (IMAP+) study. N, sample size 
participate in the IMAP+ study. This group was subdivided into two groups based on their score of self-reported SCD (see below and Fig. 1) resulting in 28 participants with a low score considered as the healthy control (HC) and 23 participants with a high score labelled as the SCDcommunity. As for the SCD-clinic, only the participants for whom the three main measures of interest were available were included in the present study.

The IMAP+ study was approved by the local ethics committee. After the complete description of the study to the participants, written informed consent was obtained from all participants.

\section{Neuropsychological assessment}

Neuropsychological assessment was performed on the same site for all participants at baseline and at followup. The mean duration between serial neuropsychological assessments was $2.4( \pm 0.8)$ years.

\section{Self- and informant-reported cognitive difficulties}

SCD was assessed with the Cognitive Difficulties Scale (CDS) [59], a 39-item self-rated questionnaire that requires participants to rate how often they experience particular cognitive difficulties in everyday life on a 5point scale (from "never" $=0$ to "very often" $=4$ ). This questionnaire was performed by the participant about himself, resulting in a self-reported measure of SCD, and by the participant's informant about the participant, resulting in an informant-reported measure of SCD. Higher scores indicate greater SCD.

In the present study, we used the reduced SCD score of the CDS [59], corresponding to the sum of 34 items, as a measure of self- or informant-reported cognitive difficulties. Five items were removed from the initial questionnaire which correspond to gendered items (e.g. related to cooking or sewing), as they depend on agespecific cultural norms [59]. This score will be referred to as 'global ${ }_{R} S C D$ ' in the following article. The selfreported global ${ }_{R} S C D$ score was used to separate the $\mathrm{HC}$ from the SCD-community. More specifically, a hierarchical clustering analysis ( 2 clusters, 50 iterations) was performed on this score within the cognitively unimpaired volunteers recruited from the community, resulting in 28 participants with a low score $(\mathrm{HC})$ and 23 participants with a high score (SCD-community).

In a previous study by our team, we conducted a factorial analysis on the CDS scale and highlighted three different factors reflecting different types of SCD [56]: (i) the first factor (F1) was composed of 11 items related to attention and language; (ii) the second factor (F2) included 12 items related to memory and orientation; and (iii) the third factor (F3) included 7 items related to praxis and domestic activities [56]. These three factors were computed for each participant using each item weighted according to the results of the factorial analysis from La Joie et al. [56] (for self- and informant-reported SCD) and compared between the groups.

\section{Psychoaffective measures}

Depressive symptomatology and trait anxiety were assessed using the Montgomery-Asberg Depression Rating Scale (MADRS) [60] and Spielberger State-Trait Anxiety Inventory (STAI-B), respectively [61]. Higher scores indicated a higher level of depression or anxiety with all scores yet keeping within the subclinical levels as participants were screened for the lack of clinically significant anxiety or depression disorders.

\section{Cognitive measures}

Global cognition was assessed using the Mini-Mental State Examination (MMSE) [62] and the global score of the Mattis Dementia Rating Scale (DRS) [63]. Memory was assessed using the Encoding, Storage and Recuperation (ESR) word list delayed recognition subscores [64].

\section{Cross-sectional data: transformation to $w$-scores}

For cross-sectional analyses, all continuous raw scores were transformed into $w$-scores, which are age and education-adjusted $z$-scores relative to the control group [65], except for the psychoaffective measures.

\section{Longitudinal data: computation of slope of changes}

For longitudinal analyses, a slope of decline was calculated for each measure of each subject with a simple linear regression equation ' $y=a x+b$ ' (where $y$ is the score of interest; $x$ is the number of months from the initial evaluation; $a$ is the slope of the line; $b$ is the intercept) [66].

\section{Neuroimaging assessment Neuroimaging data acquisition}

All participants were scanned on the same magnetic resonance imaging (MRI) and positron emission tomography (PET) cameras at the Cyceron Center (Caen, France): a Philips Achieva 3.0 T scanner and a Discovery RX VCT 64 PET-CT device (General Electric Healthcare), respectively.

High-resolution T1-weighted anatomical volumes were acquired using a 3D fast-field echo sequence (3D-T1FFE sagittal; repetition time $=20 \mathrm{~ms}$; echo time $=4.6$ $\mathrm{ms}$; flip angle $=10^{\circ} ; 180$ slices with no gap; slice thickness $=1 \mathrm{~mm}$; field of view $=256 \times 256 \mathrm{~mm}^{2}$; in-plane resolution $=1 \times 1 \mathrm{~mm}^{2}$ ). In the present study, we used the baseline and the follow-up MRI scans; the mean duration between serial MRI was 2.4 years ( \pm 0.8 years). Follow-up MRI scan was missing in $1 \mathrm{HC}, 1 \mathrm{SCD}-$ community, and 3 SCD-clinic participants.

Both ${ }^{18}$ F-fluorodeoxyglucose (FDG) and florbetapir-PET scans were acquired with a resolution of $3.76 \times 3.76 \times$ 
$4.9 \mathrm{~mm}^{3}$ (field of view $=157 \mathrm{~mm}$ ). Forty-seven planes were obtained with a voxel size of $1.95 \times 1.95 \times 3.2 \mathrm{~mm}^{3}$. A transmission scan was performed for attenuation correction before the PET acquisition. For ${ }^{18} \mathrm{~F}$-FDG-PET, the participants were fasted for at least $6 \mathrm{~h}$ before scanning. After a 30-min resting period in a quiet and dark environment, $180 \mathrm{MBq}$ of ${ }^{18} \mathrm{~F}$-FDG was intravenously injected as a bolus. A 10-min PET acquisition scan began 50 min after the injection. For florbetapir-PET, each participant underwent a 20-min PET scan, beginning 50 min after the intravenous injections of $\sim 4 \mathrm{MBq} / \mathrm{kg}$ of florbetapir. Two $\mathrm{HC}$ and 3 SCD-clinic participants only underwent a 10-min acquisition starting $50 \mathrm{~min}$ after the injection. In the present study, we used the baseline PET scans of the participants, which was missing for $1 \mathrm{HC}$ for 18F-FDG-PET and for $3 \mathrm{HC}$ and $1 \mathrm{SCD}$-community participants for florbetapir-PET (see Additional file 1).

\section{Neuroimaging pre-processing}

Cross-sectional data Neuroimaging pre-processing was performed using the Statistical Parametric Mapping version 12 (SPM12) software (Wellcome Trust Centre for Neuroimaging, London, UK).

T1-weighted MRI were segmented using multimodal segmentation (T1-weighted MRI, T2-weighted MRI, and Flair) and spatially normalized to the Montreal Neurological Institute (MNI) space. Then, the normalized grey matter segments were modulated to correct for nonlinear warping effects, and the resultant images were smoothed using an 8-mm full-width half-maximum (FWHM) Gaussian kernel [57, 67, 68].

PET data were corrected for partial volume effects using the Muller-Gartner method, coregistered onto their corresponding MRI, and normalized using the deformation parameters defined from the MRI procedure. Resultant images were quantitatively normalized using the cerebellar grey matter as the reference region. PET images were then smoothed using a 10-mm FWHM Gaussian kernel [57, 67-69].

All resultant MRI and PET images were finally masked to exclude non-grey matter voxels as well as the cerebellum from the analyses.

The global neocortical standardized uptake value ratio (SUVr) value was also obtained in each individual from the Florbetapir-PET SUVr images using a neocortex mask (including all regions but the cerebellum, hippocampus, amygdala, and subcortical grey nuclei). The SUVr was used to classify subjects as florbetapir positive or negative, using a threshold derived from an independent group of 41 young individuals from the IMAP project (16 females; age $=28.40 \pm 6.06$ years) $[25,70]$. The positivity threshold was defined by the mean $+2 \mathrm{SD}$ of 41 healthy young controls aged 21 to 39 years old (supposedly devoid of amyloid deposition), corresponding to a Florbetapir SUVr of 0.98. Individuals with values above this threshold were considered as amyloid-positive and those below this threshold as amyloid-negative.

Longitudinal changes For each participant, a brain map of atrophy progression over time, reflecting the progression of atrophy over the follow-up period, was computed using the Jacobian determinants from the pairwise longitudinal registration of the baseline and follow-up MRI scans. The method is detailed in [71] and summarized in Additional file 2.

\section{Statistical analysis}

Cross-sectional data To assess whether the control and both SCD groups differ in terms of demographic and clinical variables or self-reported global $R$ SCD, variance analyses (ANOVAs) with one three-level (group) factor were performed.

To highlight the differences between the three groups regarding the factors of interest potentially related to SCD or memory clinic consultation (i.e. psychoaffective measures, informant-reported SCD, types of SCD), we performed analyses of covariance (ANCOVAs) with one three-level (group) factor correcting for age and education, for all continuous variables-except for $w$-scores where ANOVAs were performed without covariates as age and education were already partialled out. Group differences for categorical variables were assessed using chi-square tests.

The cognitive substrates of self-reported SCD were assessed in each group using correlations, correcting for age and education for all variables but $w$-scores. Correlations were performed between self-reported global $_{R} S C D$ score and self-reported SCD factors, informant-reported global $_{R} \mathrm{SCD}$, cognitive performances (global cognition and memory $w$-scores), and psychoaffective measures (anxiety and depression). All statistical analyses of behavioural data were performed using the STATISTICA software (v13.0, StatSoft Inc., Tulsa, OK).

The cerebral substrates were assessed in each group using regression analyses correcting for age and education between the self-reported global $_{R} S C D$ score and cross-sectional MRI and PET (FDG and Florbetapir) data. All statistical analyses of neuroimaging data were performed using the full factorial design in SPM12.

Longitudinal data To determine whether SCD, cognitive, and psychoaffective measures significantly changed over time, the individual slopes of regression line were compared to zero for each SCD group separately, using one-sample $t$ tests. Then, to assess whether the changes in these measures significantly differed between the groups, the slopes of regression line were compared between the groups using ANCOVAs with one two-level 
(group) factor, correcting for age and education, for each SCD, cognitive, and psychoaffective measures. Thirdly, to assess whether the atrophy progression over time significantly differed between the groups, an ANCOVA with one three-level (group) factor with age and education as covariates was performed in SPM12. Finally, to improve our understanding of the predictors of cognitive decline, regression analyses were performed within each SCD group between baseline SCD scores or psychoaffective measures and the slope of cognitive decline, correcting for age and education, using general linear models and the STATISTICA software.

Neuroimaging results are examined at $p_{\text {uncorrected }}<0.005$ and cluster extent $k>250 \mathrm{~mm}^{3}$ also indicating results surviving the $p<0.001$ and $k>50 \mathrm{~mm}^{3}$ threshold. This allows to take into account the clusters that were less significant but larger versus more significant but smaller. For behavioural results, when the main effect of the group was significant $(p<0.05)$, post-hoc analyses were performed using the Newman-Keuls method.

\section{Results}

\section{Group characteristics}

There was no between-group difference in any demographic or cognitive variables; only a trend was found for SCD-clinic to be younger than $\mathrm{HC}$ and SCDcommunity to have a higher amyloid proportion of amyloid-positive individuals (Table 1). The self-reported global $_{R}$ SCD score was higher in SCD-clinic compared to $\mathrm{HC}$ but equivalent in both SCD groups (Fig. 2a).

\section{Cross-sectional data}

At baseline, the self-reported SCD differed significantly between the groups for the global ${ }_{R}$ score and the three factors. HC showed lower self-reported SCD than both SCD groups; note that self-reported global ${ }_{R} S C D$ was used to separate $\mathrm{HC}$ from SCD-community. As for the informant-reported SCD, SCD-clinic had higher scores than SCD-community and $\mathrm{HC}$, and SCD-community had higher scores than $\mathrm{HC}$, for all SCD measures except for the praxis-domestic activities SCD for which no difference was found between the SCD groups (see Fig. 2b). The two psychoaffective measures showed significant betweengroup differences: for anxiety, scores were significantly higher in SCD-community and SCD-clinic compared to $\mathrm{HC}$; for depression, SCD-clinic had higher scores than SCD-community and HC (see Fig. 2c, d).

\section{Substrates of self-reported SCD Cognitive and behavioural correlates}

Significant relationships were found between selfreported global $_{R}$ SCD score and each self-reported SCD factors in both SCD groups. Significant correlations were found between self-reported global $\mathrm{R}_{\mathrm{S}} \mathrm{SCD}$ and the corresponding measures of informant-reported SCD only in the SCD-clinic. A significant relationship was also found between the self-reported global $\mathrm{R}_{\mathrm{R}} \mathrm{SCD}$ score and anxiety in the SCD-community group, while no relationship was found with baseline objective measures of cognition or depression in any group (Table 2).

\section{Brain correlates}

In the SCD-community group, self-reported global $_{R} S C D$ negatively correlated with glucose metabolism and grey matter volume in the left insula, right superior frontal, and anterior cingulate cortex (Fig. 3a). Except for the right superior frontal correlation with grey matter volume, all

Table 1 Demographic features of the study populations

\begin{tabular}{|c|c|c|c|c|}
\hline & $\mathrm{HC}$ & SCD-community & SCD-clinic & ANOVAs, $p$ value \\
\hline $\bar{N}$ & 28 & 23 & 27 & \\
\hline Female $\%(N)$ & $46(13)$ & $61(14)$ & $41(11)$ & $\left(x^{2}\right) N S^{n}$ \\
\hline Age & $72.25 \pm 6.33$ & $71.70 \pm 6.60$ & $68.30 \pm 7.99$ & 0.09 \\
\hline Level of education & $11.50 \pm 3.64$ & $12.65 \pm 4.13$ & $12.85 \pm 3.60$ & 0.37 \\
\hline MMSE & $28.68 \pm 1.09$ & $28.70 \pm 1.18$ & $28.70 \pm 1.27$ & 0.99 \\
\hline DRS & $0.05 \pm 1.02$ & $0.08 \pm 0.58$ & $-0.12 \pm 0.90$ & 0.68 \\
\hline ESR & $-0 \pm 0.71$ & $0.01 \pm 0.72$ & $-0.49 \pm 1.70$ & 0.18 \\
\hline APOE $\varepsilon 4$ (carrier) \% (N) & $18(5)$ & $26(6)$ & $15(4)$ & $\left(X^{2}\right) N S^{a}$ \\
\hline Amyloid status (pos) \% (N) & $22(6)$ & $45(10)$ & $33(9)$ & $\left(X^{2}\right) N S^{\alpha}$ \\
\hline SUVr & $0.97 \pm 0.17$ & $1.03 \pm 0.18$ & $1.01 \pm 0.19$ & 0.46 \\
\hline
\end{tabular}

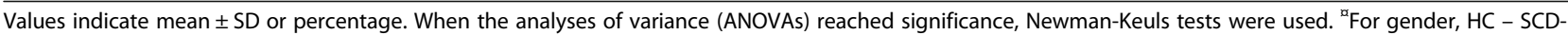
community $p=0.29, \mathrm{HC}$ - SCD-clinic $p=0.71$, SCD-community - SCD-clinic $p=0.16$; for APOE4 carrier: HC - SCD-community $p=0.49$, HC - SCD-clinic $p=0.76$, $\mathrm{SCD}$-community - SCD-clinic $p=0.33$; for amyloid status: HC - SCD-community 0.09, HC - SCD-clinic $p=0.37$, SCD-community - SCD-clinic $p=0.39$ Abbreviations: APOE \&4 apolipoprotein E allele 4, DRS $w$-score of Mattis Dementia Rating Scale, ESR $w$-score of Encoding, Storage and Recuperation, HC healthy control, MMSE Mini-Mental State Examination, $N$ sample size, NS not significant, pos positive, SCD subjective cognitive decline, SD standardized deviation 
A $\quad$ Self-reported SCD

GlobalR $p<0.001 ; F 1 p<0.001 ; F 2 p<0.001 ; F 3 p<0.001$

$\square \mathrm{HC} \square \mathrm{SCD}-$-community $\square \mathrm{SCD}-$-clinic

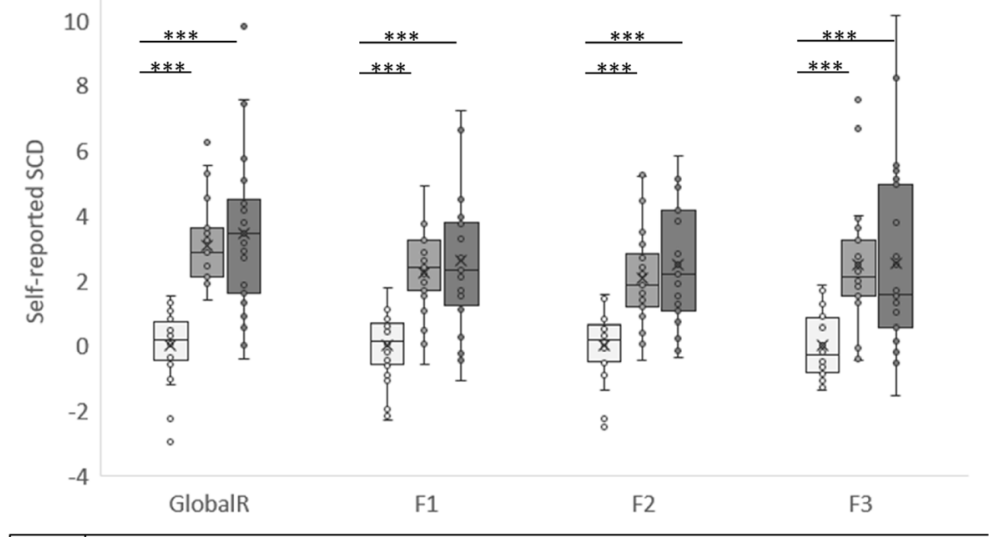

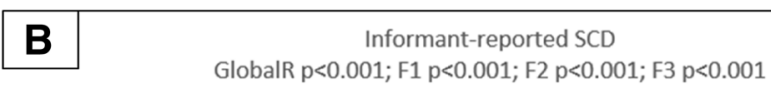

口HC $\square$ SCD-community $\square$ SCD-clinic
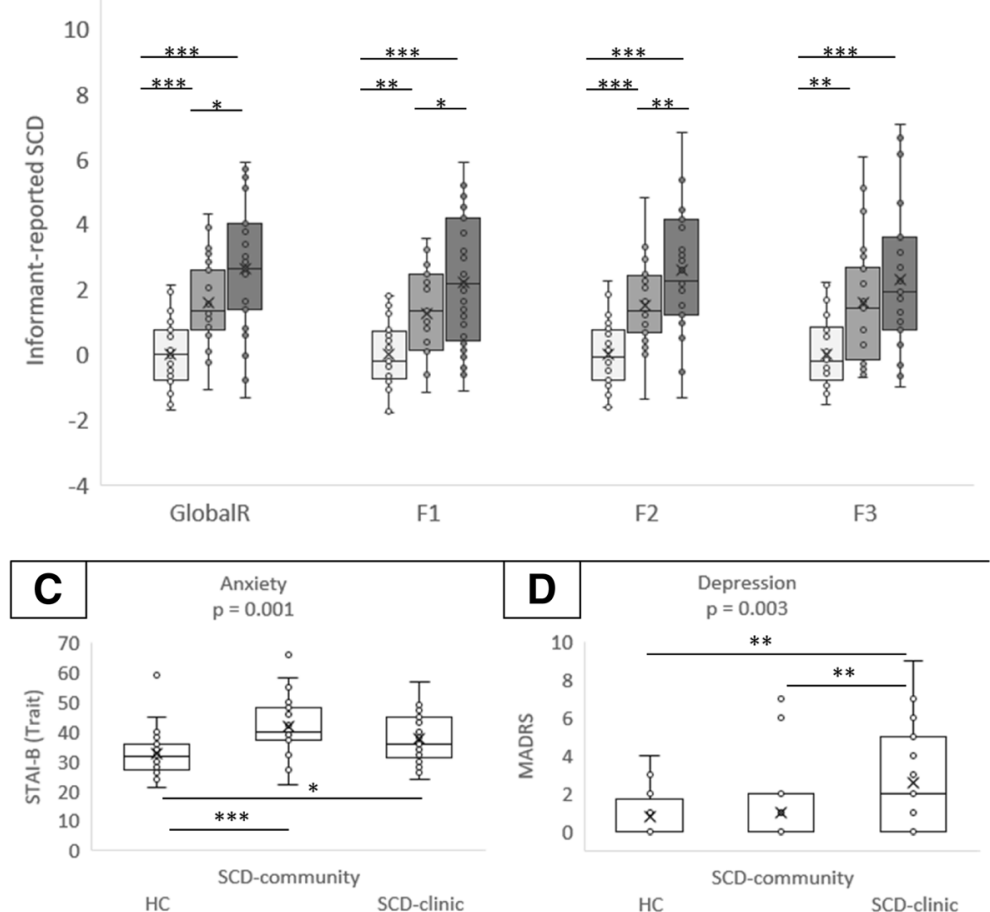

Fig. 2 Group comparisons on subjective cognitive decline (SCD) and psychoaffective measures. The graphs indicate mean values and 95\% confidence intervals. a Group comparisons on the global $\left.\right|_{R}$ and the three self-reported SCD factors. $\mathbf{b}$ Group comparisons on the global ${ }_{R}$ and the three informantreported SCD factors. c Group comparison on subclinical anxiety. $\mathbf{d}$ Group comparison on subclinical depression. $\mathbf{a}$, $\mathbf{b} p$ corresponds to one-way analysis of variance (ANOVA); post-hoc analyses were performed with the Newman-Keuls difference test. Higher scores indicate greater SCD. $\mathbf{c}, \mathbf{d} p$ corresponds to one-way analysis of covariance (ANCOVA) correcting for age and education; post-hoc analyses were performed with the Newman-Keuls difference test. Higher scores indicate higher subclinical anxiety or depression. ${ }^{*} p<0.05,{ }^{* *} p<0.01,{ }^{* * *} p<0.001$ between the groups. F1, factor 1 attention-language SCD; F2, factor 2 memory-orientation SCD; F3, factor 3 praxis-domestic activities SCD; MADRS, Montgomery-Asberg Depression Rating Scale; STAI-B, Spielberger State-Anxiety Inventory Trait 
Table 2 Results of linear regressions or general linear models between self-reported global $\mathrm{R} C \mathrm{C}$ and cross-sectional measures

\begin{tabular}{|c|c|c|c|c|}
\hline & \multicolumn{2}{|c|}{ SCD-community } & \multicolumn{2}{|c|}{ SCD-clinic } \\
\hline & $r$ & $p$ & $r$ & $p$ \\
\hline \multicolumn{5}{|l|}{ Self-reported SCD } \\
\hline Attention-language SCD (F1) & 0.62 & 0.003 & 0.88 & $<0.001$ \\
\hline Memory-orientation SCD (F2) & 0.70 & $<0.001$ & 0.90 & $<0.001$ \\
\hline Praxis-domestic activities SCD (F3) & 0.56 & 0.008 & 0.67 & $<0.001$ \\
\hline \multicolumn{5}{|l|}{ Informant-reported SCD } \\
\hline Global $_{R}$ SCD & 0.10 & 0.66 & 0.68 & $<0.001$ \\
\hline \multicolumn{5}{|l|}{ Cognitive measures } \\
\hline DRS & -0.10 & 0.67 & 0.14 & 0.48 \\
\hline ESR & -0.25 & 0.25 & -0.14 & 0.48 \\
\hline \multicolumn{5}{|l|}{ Psychoaffective measures } \\
\hline STAI-B & 0.49 & 0.02 & -0.03 & 0.90 \\
\hline MADRS & -0.01 & 0.96 & -0.15 & 0.47 \\
\hline
\end{tabular}

For the informant-reported SCD and cognitive measures, values indicate the results of the simple linear regressions ( $r$ and $p$ values) between the selfreported global $_{R} S C D$ score on the one hand and the corresponding variables on the other hand. For the psychoaffective measures, values indicate the results of the general linear model between the self-reported global ${ }_{R} S C D$ score and these measures, correcting for age and education. Values indicated in italics correspond to $p<0.05$

Abbreviations: DRS w-score of Mattis Dementia Rating Scale, ESR w-score of Encoding, Storage and Recuperation, $F 1 w$-score of cognitive difficulties scale factor 1 attention-language SCD, F2 $w$-score of cognitive difficulties scale factor 2 memory-orientation SCD, F3 $w$-score of cognitive difficulties scale factor 3 praxis-domestic activities SCD, MADRS Montgomery-Asberg Depression Rating Scale, SCD subjective cognitive decline, STAI-B Spielberger State-Anxiety Inventory Trait clusters were recovered at $p<0.001, k>50$ voxels (Additional file 3).

In the $\mathrm{SCD}$-clinic group, the self-reported global $_{\mathrm{R}}$ SCD negatively correlated with glucose metabolism in the bilateral insula, left medial prefrontal cortex (encompassing both the ventral and dorsal sections), bilateral superior and middle temporal cortex, and right fusiform gyrus. All clusters were recovered at $p<0.001$, $k>50$ voxels, except for the left medial prefrontal cortex (Additional file 3). At the threshold of $p<0.005$ and $k>250$ voxels, no correlation was found with amyloid deposition or grey matter volume (see Fig. 3b).

For the sake of comparison, the correlations were also assessed with the SCD factors; they showed that the brain substrates of the self-reported memory SCD score were very similar to those of the global $_{R}$ SCD score (Additional file 3).

\section{Longitudinal data}

\section{Cognitive and behavioural measures}

The self-reported praxis-domestic activities SCD slope was significantly higher than zero $(p=0.04)$, i.e. this measure significantly increased over time, only in the SCD-clinic. By contrast, the depression score slope tended to be higher than zero $(p=0.06)$ only in the SCD-community. None of the other slopes significantly differed from zero indicating that none of the other self- and informant-reported SCD factors and cognitive or psychoaffective measures significantly changed over time during the follow-up period of the SCD groups (Table 3).

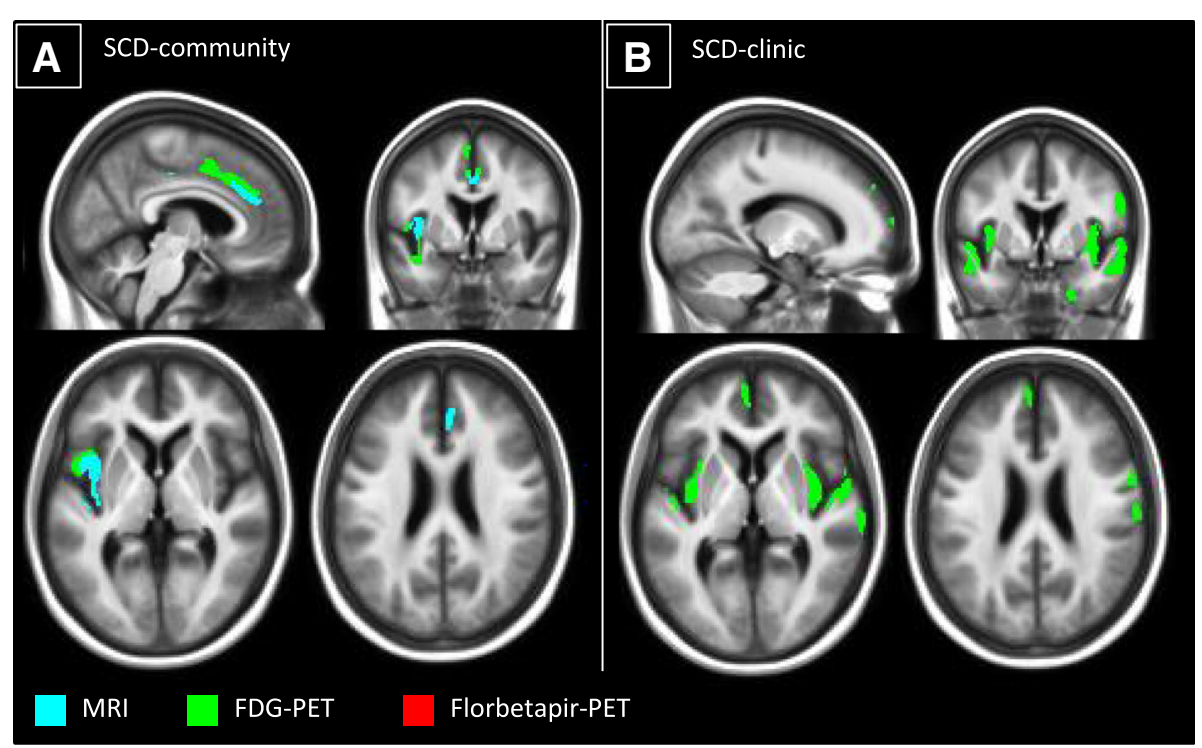

Fig. 3 Results of the voxelwise correlations between self-reported global ${ }_{R} S C D$ and neuroimaging within each SCD group. The correlations with grey matter volume (blue), glucose metabolism (green), and amyloid deposition (red) are presented within the SCD-community (a) and the SCDclinic (b) groups. The results are displayed at uncorrected $p<0.005, k>250$ voxels. FDG, 18F-fluorodeoxyglucose; PET, positron emission tomography; SCD, subjective cognitive decline 
At follow-up, there was no significant group difference for any cognitive, psychoaffective, or SCD slope of changes, except for the self-reported praxis-domestic activities SCD which increased more in the SCD-clinic group than in the SCD-community group (Table 3 ).

\section{Atrophy progression over time in MRI}

Between-group comparisons of brain maps of atrophy progression over time showed that SCD-clinic had higher atrophy progression over time in the dorsal frontal cortex compared to $\mathrm{HC}$ (Fig. 4b) and in the middle temporal cortex and dorsal frontal cortex extending to the ventral prefrontal cortex compared to SCDcommunity (Fig. 4c). There was no significant difference in the atrophy progression over time between $\mathrm{HC}$ and SCD-community (Fig. 4a). All clusters were recovered at $p<0.001, k>50$ voxels (Additional file 4).

\section{Predictors of cognitive decline}

Regression analyses between the slope of cognitive decline and baseline measures showed that a high self-reported global $_{\mathrm{R}}(r=-0.59, p=0.007)$ or memory $(r=-0.52, p=0.02)$ SCD at baseline correlated with a higher global cognitive decline only in the SCDcommunity group. No baseline measures predicted the evolution of cognitive performances in the SCDclinic group (Additional file 5).

\section{Discussion}

The type of recruitment of SCD patients might have a significant impact on the characteristics, aetiology, and risk of Alzheimer's clinical syndrome of the recruited SCD sample. Yet, the characteristics specifically associated with help-seeking behaviour in SCD have only been assessed in a few studies [25, 72-76], and most of these studies were not restricted to elders with formally assessed normal cognitive performances, few of them included the role of the informant or neuroimaging biomarkers and none included longitudinal data. This study thus aimed at identifying the characteristics of SCD individuals according to their type of recruitment (SCD-community versus SCD-clinic) in terms of crosssectional and longitudinal self- and informant-reported $\mathrm{SCD}$, subclinical anxiety and depression, cognitive performances, and atrophy progression over time, all known to increase the risk of being at a preclinical stage of Alzheimer's syndrome [1, 43, 49-54, 77, 78]. We also assessed the substrates of self-reported SCD within each group to identify the main respective drivers of their

Table 3 Description of the progression over time of SCD, cognitive, and psychoaffective measures within each group

\begin{tabular}{|c|c|c|c|c|c|}
\hline Scores & $N$ & SCD-community & $N$ & SCD-clinic & ANCOVAs, $p$ value \\
\hline Follow-up duration, years (behavioural measures) & 22 & $2.45 \pm 0.67$ & 25 & $2.36 \pm 0.95$ & 0.32 \\
\hline Follow-up duration, years (neuroimaging measures-MRI) & 22 & $2.55 \pm 0.67$ & 24 & $2.28 \pm 0.78$ & 0.22 \\
\hline \multicolumn{6}{|l|}{ Self-reported SCD slopes } \\
\hline Global $_{R}$ & 22 & $-0.08 \pm 0.27$ & 20 & $0.08 \pm 0.35$ & 0.11 \\
\hline Attention-language (F1) & 22 & $0.009 \pm 0.06$ & 20 & $0.02 \pm 0.11$ & 0.60 \\
\hline Memory-orientation (F2) & 22 & $-0.03 \pm 0.09$ & 20 & $0.004 \pm 0.12$ & 0.28 \\
\hline Praxis-domestic activities (F3) & 22 & $-0.009 \pm 0.07$ & 20 & $0.04 \pm 0.09^{\#}$ & 0.04 \\
\hline \multicolumn{6}{|l|}{ Informant-reported SCD slopes } \\
\hline Global $_{R}$ & 15 & $0.06 \pm 0.46$ & 16 & $0.07 \pm 0.65$ & 0.98 \\
\hline Attention-language (F1) & 15 & $-0.02 \pm 0.13$ & 16 & $0.01 \pm 0.2$ & 0.65 \\
\hline Memory-orientation (F2) & 15 & $0.02 \pm 0.12$ & 16 & $-0.007 \pm 0.12$ & 0.61 \\
\hline Praxis-domestic activities (F3) & 15 & $0.03 \pm 0.15$ & 16 & $0.02 \pm 0.1$ & 0.94 \\
\hline \multicolumn{6}{|l|}{ Slope of cognitive change } \\
\hline DRS & 22 & $-0.02 \pm 0.14$ & 25 & $-0.03 \pm 0.11$ & 0.74 \\
\hline ESR & 22 & $0.0005 \pm 0.03$ & 24 & $-0.02 \pm 0.09$ & 0.27 \\
\hline \multicolumn{6}{|l|}{ Slope of psychoaffective changes } \\
\hline STAI-B & 22 & $-0.04 \pm 0.21$ & 25 & $0.05 \pm 0.22$ & 0.16 \\
\hline MADRS & 22 & $0.09 \pm 0.20$ & 23 & $0.08 \pm 0.26$ & 0.92 \\
\hline
\end{tabular}

The values indicate the mean \pm SD of the slope of evolution between baseline and follow-up. When ANCOVAs correcting for age and education reached significance, values are indicated in italics $(p<0.05)$

Abbreviations: ANCOVAs analyses of covariance correcting for age and education, CDS Cognitive Difficulties Scale, DRS Mattis Dementia Rating Scale, ESR Encoding, Storage and Recuperation, F1 factor 1 attention-language SCD, F2 factor 2 memory-orientation SCD, F3 factor 3 praxis-domestic activities SCD, HC healthy control, MADRS Montgomery-Asberg Depression Rating Scale, MRI magnetic resonance imaging, $N$ sample size, $S C D$ subjective cognitive decline, $S D$ standardized deviation, STAI-B Spielberger State-Anxiety Inventory Trait

"The slope is significantly different from zero $(p<0.05)$ 


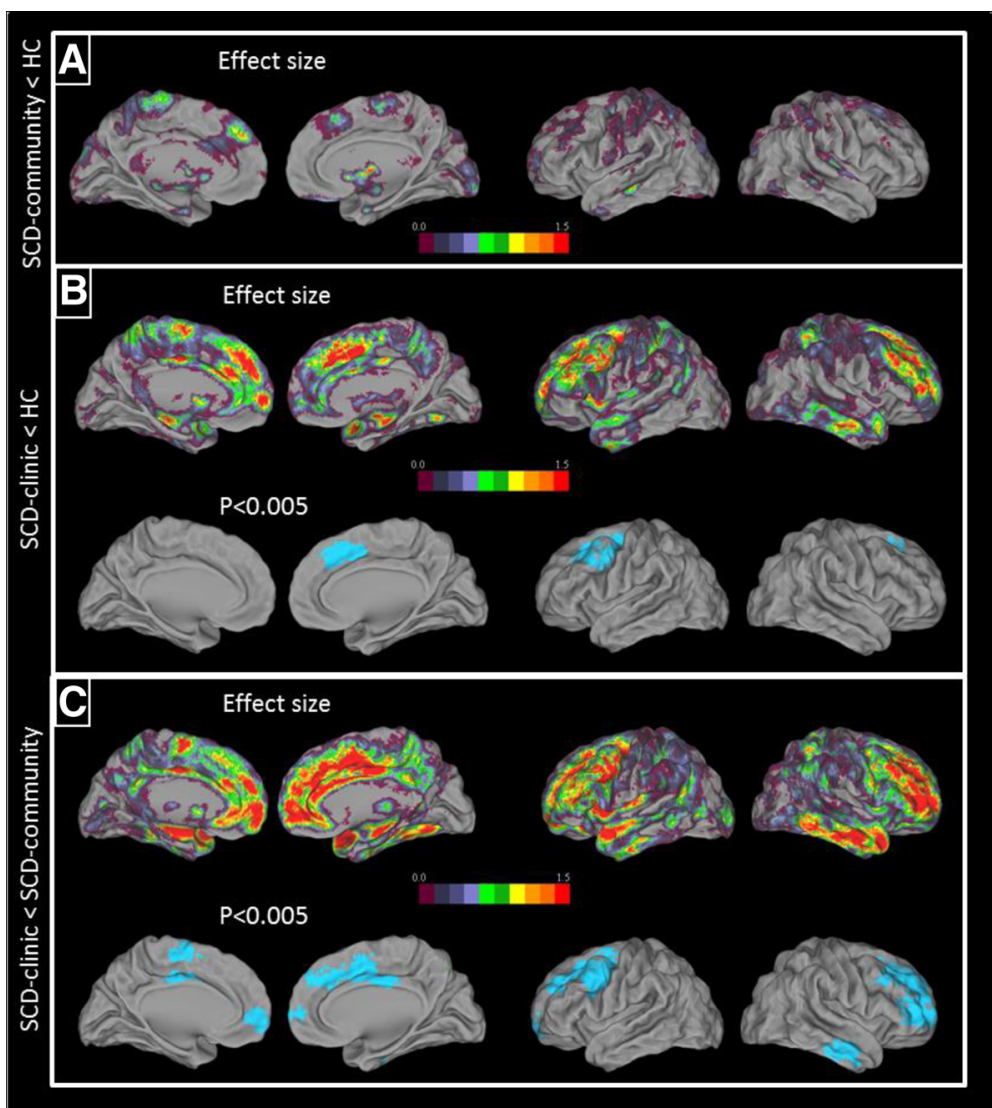

Fig. 4 Results of the between-group comparisons of brain maps of atrophy progression over time. Voxelwise comparisons showed the regions of significantly higher atrophy progression over time in SCD-community as compared to healthy control (HC) (a) and in SCD-clinic as compared to HC (b) and to SCD-community (c). The results are displayed as $T$ value maps thresholded at uncorrected $p<0.005, k>250$ voxels and as effect size maps. SCD, subjective cognitive decline

SCD which could include risk factor of Alzheimer's clinical syndrome [25] or psychological distress [39].

\section{Common points between the SCD groups}

The two SCD groups presented similar characteristics, although the recruitment setting differs. Thus, at a comparable level of self-reported global $_{R}$ SCD, both SCD groups showed a higher level of subclinical anxiety and a higher level of informant-reported global ${ }_{R} S C D$ but similar cognitive performances compared to controls. Hence, in both SCD groups, the self-reported global $_{R}$ SCD correlated to the three factors-suggesting that they are not driven by the subjective decline in the distinct cognitive domain-but surprisingly not to any objective measure of cognition. This highlights the relevance of the self- and informant-reported SCD, which might be sensitive to subtle cognitive changes not yet detectable using objective measures $[46,49,50]$. No significant change in cognition was found in any group, which might reflect the fact that the follow-up period $(2.4 \pm 0.8$ years $)$ was too short to capture subtle cognitive decline.
Surprisingly, our findings also showed no difference between the groups in term of amyloid status or $\mathrm{SUVr}$ uptake values. In contrast to previous studies, the selfreported SCD was not associated with the presence of amyloid deposition in cognitively unimpaired elders recruited from the community $[18,20,21,23,25]$ or in SCD-clinic patients [22, 25]. However, this effect seems subtle and might depend on the sample and the measurement used [21, 22], as other studies have reported negative results like ours $[79,80]$ compared with controls, or found an association only in APOE $\varepsilon 4$ carriers [81, 82]. Interestingly, when merging our two SCD groups together, a significant between-group difference was found with higher amyloid SUVr in the SCD compared to the controls $(p=0.044$, Additional file 6). The lack of difference between the SCD groups might also be due to the fact that the SCD-clinic tended to be younger (about 68.3 years old in SCD-clinic against 71.70 in SCD-community and 72.25 in controls), and the proportion of APOE $\varepsilon 4$ carriers was relatively small in the SCD-clinic (15\%) compared to the SCD-community $(26 \%)$ or the controls $(18 \%)$; when the analyses were 
corrected for age, level of education, and APOE $\varepsilon 4$ status, a general trend appeared in the between-group comparison of amyloid SUVr $(p=0.096$, Additional file 6).

\section{Specificities of both SCD groups Specificities of the SCD-community}

While the SCD-community share similarities with the SCD-clinic, our findings also highlight the differences. Thus, the SCD-community showed a higher subclinical anxiety than older adults without subjective cognitive decline. Moreover, their anxiety score correlated with their level of self-reported global ${ }_{R} S C D$ which itself predicted their subsequent cognitive decline. This suggests that anxiety contributes to the level of SCD only in the SCD-community group, while psychoaffective factors do not influence SCD in the SCD-clinic group. Neuroimaging correlates confirmed this view in showing a link between SCD and frontal grey matter volume and glucose metabolism in SCD-community, while it rather involved the temporal and parietal brain regions sensitive to $\mathrm{AD}[19,57,83]$ in the SCD-clinic group. As suggested in previous studies $[39,84-86]$, the subjective cognitive decline of SCD-community thus seems to be more strongly related to the psychoaffective factors.

\section{$S C D$-clinic seems to be a frailer population than $S C D$ - community}

By contrast, a few evidence suggest that SCD-clinic might be a frailer population than SCD-community. Thus, cognitively unimpaired older adults with subjective cognitive decline who referred to a memory clinic were characterized by higher informant-reported global $_{R}$ $\mathrm{SCD}$, higher depressive symptoms, and greater subsequent atrophy progression over time than those with the same level of SCD but who did not refer to a memory clinic. Moreover, SCD-clinic tended to show a more generalized profile of SCD. Indeed, while their level of self-reported SCD was similar to SCD-community, they showed a significant increase in praxis-domestic activities SCD over the follow-up period.

In a previous study [25], we showed that subclinical depression and (notably hippocampal) atrophy were specifically associated with medical help-seeking, suggesting that those who consult are at a higher risk of developing Alzheimer's clinical syndrome, as indicated in another study which compared the rates of incident dementia [37]. In the present study, our findings reinforced this view by showing greater atrophy progression over time. The atrophy progression over time was significantly higher in the frontal cortex and tended to be higher in the temporal lobe and particularly in the hippocampus (see effect size on Fig. 4). It might thus reflect accelerated brain ageing related to psychoaffective factors, as the frontal areas are known to be sensitive to ageing
[84-86] and commonly associated with subclinical anxiety [87] and depression [88]-themselves associated with increased risk for cognitive decline or dementia $[27,33]$. These findings might also reflect, to a lesser extent, increased risk for dementia, as greater hippocampal atrophy progression over time is known to be associated with subsequent cognitive decline [89] and dementia [90]. Similarly, the fact that they showed greater praxisdomestic activities SCD over time might also represent an additional evidence for this statement. Thus, as multidomain amnestic $\mathrm{MCI}$ are known to be more at risk of $\mathrm{AD}$ than single-domain $\mathrm{MCI}$ [91], the generalization of SCD in the SCD-clinic group might alike indicate that they are in a more advanced stage of SCD and possibly represent a frailer population than SCD-community, with an increased risk of cognitive decline, and potentially Alzheimer's clinical syndrome. These are yet only indirect evidences and longer-term follow-up in larger samples are needed to confirm this hypothesis.

\section{SCD-community and SCD-clinic: a continuum or distinct entities?}

One possible interpretation of our findings is that SCDcommunity represents an intermediate stage in a continuum leading to SCD-clinic. Indeed, they showed intermediate levels of informant-reported global ${ }_{R} S C D$, and their level of subclinical depression tended to increase at follow-up $(p=0.06)$, reaching the level of depression of the SCD-clinic $(p=0.25$, data not shown). While their neural correlates for self-reported global $_{R}$ SCD were different from SCD-clinic for some brain regions, there were also common functional brain correlates (in the insula and frontal cortex) between both SCD groups.

The intermediate level of informant-reported global $_{R}$ SCD in the SCD-community highlights the sensitivity of this measure to capture subtle differences between the SCD groups that refer or not to a memory clinic. Previous studies have shown that the informant-reported SCD can be associated with longitudinal cognitive decline [49] and a higher risk of subsequent conversion to MCI or $A D$ dementia [50, 92]; suggesting that both groups show risk factors for Alzheimer's clinical syndrome. Moreover, this is consistent with the fact that the self-reported SCD measure predicted the level of subsequent cognitive decline in the SCD-community, adding to the risk.

As regards to psychoaffective factors, a higher level of subclinical anxiety compared to controls characterized both SCD groups, while the level of subclinical depression was higher only in the SCD-clinic group at baseline and increased from baseline to follow-up in the SCD-community. As a whole, our findings suggest that referring to a memory clinic is associated with subclinical depression rather than with the level of subclinical 
anxiety or self-reported SCD. Interestingly, both psychoaffective factors (depressive symptoms and subclinical anxiety) are frequently associated with early cognitive deficits $[53,93,94]$ or subsequent dementia $[51,54]$ and could be a prodromal sign of Alzheimer's clinical syndrome [55]. However, the causal link between self- and informant-reported SCD, psychoaffective factors, and cognitive or brain changes is unclear. SCD and frontal atrophy might lead to an increase in subclinical anxiety and depression, themselves associated with an increase in informant-reported SCD, leading to memory consultation. Alternatively, psychoaffective factors might lead to, or exacerbate, brain and cognitive decline underlying self- and informant-reported SCD and stimulating memory consultation. Further studies are needed to better understand the sequence of events and causal relationships between these different factors. Specifically, a better understanding of the role of psychoaffective factors is important for the development of nonpharmacological interventions targeting emotional regulation processes [95].

Altogether, our results suggest that the two SCD groups have specificities but may represent in fact different stages of progressive cognitive decline that may lead to Alzheimer's clinical syndrome. As for early and late MCI [28, 96], SCD-community and SCD-clinic might represent two stages of SCD in a continuum that would lead, for part of them, to Alzheimer's clinical syndrome. However, we cannot exclude the alternative hypothesis that, instead of a continuum, the two groups represent distinct selections of individuals with SCD where underlying neuropsychiatric/non-AD aetiologies versus $A D$ pathology are differently represented.

\section{Strengths, limitations, and perspectives}

The major strengths of this study are its multimodal dimension and the combination of cross-sectional and longitudinal setup. Indeed, the availability of standardized assessment of a broad range of factors potentially related to SCD, including various biomarkers, provides novel insights into the integrated characterization of SCD in the context of preclinical AD/Alzheimer's syndrome. However, although based on the recommendations of Jessen et al., 2014, which list the specific features that increase the likelihood of the presence of preclinical $\mathrm{AD} /$ Alzheimer's syndrome in individuals with SCD $[1,45]$ and a previous study [56], the threshold used to separate SCD-community from controls was somewhat arbitrary. In addition, all the questionnaires were self-completed, and the sample sizes and follow-up time were relatively limited, resulting in a limited statistical power. Consequently, the statistics were not corrected for multiple comparisons which increase the risk for false positive. Therefore, our results should be interpreted with caution and validated in future studies with larger group sizes and longer follow-up time. This would also allow the assessment of the sequential and causal relationships between the different factors to understand the role of psychoaffective factors and informant-reported SCD, but also to confirm that SCDcommunity and SCD-clinic are two stages of a continuum in preclinical Alzheimer's syndrome. Nowadays, characterizing and discriminating preclinical Alzheimer's syndrome from the 'worried well' seems especially important for the early detection of persons in the preclinical stage of dementia, the prevention, and the development of efficient therapies. Given the heterogeneity of the aetiology and presentation of SCD $[1,25,45,46]$, a better understanding of these two populations might help us to identify the potential targets for pharmacological or nonpharmacological interventions.

\section{Conclusions}

As a whole, our results point to the SCD-clinic as a frailer population showing faster atrophy over time, compared to $\mathrm{HC}$ and SCD-community, which might reflect an increased risk for later cognitive decline. Depression symptoms were also higher in the SCD-clinic, but they increased over time in the SCD-community, suggesting a continuity between SCD groups. Alternatively, they might reflect distinct populations with different proportion of possible aetiologies (AD pathology, neuropsychiatric aetiologies, etc.). From a clinical standpoint, SCD patients might thus benefit from a closer clinical follow-up; from a research standpoint, this population could enrich interventional clinical trials on SCD with more participants at risk of $\mathrm{AD} /$ dementia. Finally, our findings highlight the relevance of psychoaffective factors, including both subclinical anxiety and depression, at this stage. Rather than confounding factors of SCD, psychoaffective factors might represent early symptoms of Alzheimer's clinical syndrome, or even the expression of a pathological process associated with psychological distress and related to subsequent cognitive decline in the SCD-community. This, along with the fact that they are associated with increased risk of dementia, highlights the relevance of treating these symptoms in the elderly. Further studies are yet needed to better understand their causal and/or consequent role within the different SCD stages.

\section{Additional files}

Additional file 1: Population sizes at the various imaging examination time points: cross-sectional and longitudinal neuroimaging assessments. Abbreviations: $\mathrm{HC}$ healthy control, SCD subjective cognitive decline, N sample size, MRI magnetic resonance imaging, PET positron emission tomography, FDG 18F-fluorodeoxyglucose. (DOCX $46 \mathrm{~kb}$ ) 
Additional file 2: Description of the methodology of the longitudinal neuroimaging data processing. (DOCX $16 \mathrm{~kb}$ )

Additional file 3: Glass brain of the voxelwise correlations between selfreported SCD and neuroimaging within each SCD group. The correlations between self-reported SCD measures (1, Global $\mathrm{R}_{R} \mathrm{SCD} ; 2$, Attention/Language SCD; 3, Memory/Orientation SCD; 4, Praxis/Domestic Activities SCD) and grey matter volume (MRI), glucose metabolism (FDG-PET), or amyloid deposition (Florbetapir-PET) are presented within the SCD-community (A) and the SCD-clinic (B) groups. The results are displayed at uncorrected $p<$ $0.005, k>250$ voxels and $p<0.001, k>50$ voxels for all analyses. FDG $18 \mathrm{~F}-$ fluorodeoxyglucose, PET positron emission tomography, SCD subjective cognitive decline. (DOCX $538 \mathrm{~kb}$ )

Additional file 4: Glass brains of the between-group comparisons of brain maps of atrophy progression over time. Voxelwise comparisons show the regions of significantly higher atrophy progression over time in SCD-community as compared to healthy control (HC) (A), and in SCDclinic as compared to HC (B) and to SCD-community (C). The results are displayed as $T$ value maps thresholded at uncorrected $p<0.005, k>250$ voxels and $p<0.001, k>50$ voxels. SCD Subjective cognitive decline. (DOCX $267 \mathrm{~kb}$ )

Additional file 5: Results of the general linear model assessing the links between baseline variables and cognitive decline slopes. The values indicate the results of the general linear model assessing the links between baseline self- and informant-reported SCD factors or psychoaffective measures and the slope of cognitive decline, corrected for age and education. Values indicated in bold correspond to $p<0.05$. Abbreviations: DRS Mattis Dementia Rating Scale, ESR Encoding, Storage and Recuperation, F1 score of cognitive difficulties scale factor 1 attention-language SCD, F2 score of cognitive difficulties scale factor 2 memory-orientation SCD, F3 score of cognitive difficulties scale factor 3 praxis-domestic activities SCD, MADRS Montgomery-Asberg Depression Rating Scale, SCD subjective cognitive decline, STAI-B Spielberger StateAnxiety Inventory Trait. (DOCX $21 \mathrm{~kb})$

Additional file 6: Group comparisons on amyloid SUVr. Graphs indicate mean values and $95 \%$ confidence intervals. A: three-group comparisons on the amyloid SUVr and post-hoc analyses performed with the Newman-Keuls test; B: two-group comparisons on the amyloid SUVr, when SCD groups were merged. ANCOVA analysis of variance corrected, APOE apolipoprotein E, HC healthy control, SCD subjective cognitive decline, SUVr standardized uptake value ratio. (DOCX $77 \mathrm{~kb}$ )

\section{Abbreviations}

AD: Alzheimer's disease; ANCOVA: Analysis of covariance; ANOVA: Analysis of variance; $\mathrm{APOE}$ ع4: Apolipoprotein E allele 4; Aß: Amyloid deposition; CDS: Cognitive Difficulties Scale; DRS: Mattis Dementia Rating Scale; ESR: Encoding, Storage and Recuperation; F1: Factor 1 of CDS corresponding to attention-language SCD; F2: Factor 2 of CDS corresponding to memoryorientation SCD; F3: Factor 3 of CDS corresponding to praxis-domestic activities SCD; FDG: 18F-fluorodeoxyglucose; FWHM: Full-width half-maximum; HC: Healthy controls; IMAP+: Imagerie Multimodale de la maladie d'Alzheimer Précoce; MADRS: Montgomery-Asberg Depression Rating Scale; MCI: Mild cognitive impairment; MMSE: Mini-Mental State Examination; MNI: Montreal Neurological Institute; MRI: Magnetic resonance imaging; N: Size; NS: Not significant; PET: Positron emission tomography; Pos: Positive; SCD: Subjective cognitive decline; SCD-clinic: Subjective cognitive decline recruited from a memory clinic; SCD-community: Subjective cognitive decline recruited from volunteers from the community; SCD-l: Subjective Cognitive Decline Initiative; SD: Standard deviation; SPM12: Statistical Parametric Mapping version 12; STAI-B: Spielberger State-Trait Anxiety Inventory-B; SUVr: Standardized uptake value ratio

\section{Publisher's Note}

Springer Nature remains neutral with regard to jurisdictional claims in published maps and institutional affiliations.

\section{Acknowledgements}

The authors thank F. Eustache, E. Arenaza-Urquijo, J. Gonneaud, R. De Flores, J. Mutlu, C. André, V. Ourry, F. Mézenge, M. Leblond, T. Anquetil, K. Mevel, N. Villain, M. Fouquet, A. Quillard, C. Schupp, J. Dayan, A. Chocat, JC. Baron, F.
Viader, A. Pélerin, M. Gaubert, S. Egret, M. Delarue, G. Rauchs, A. Abbas, L. Barre, A. Manrique, D. Guilloteau, and the Cyceron staff members for their help with the data acquisition and the volunteers who were included in this study.

\section{Authors' contributions}

EK and IM performed the analyses, contributed to the data interpretation, and wrote the first draft of the manuscript. $\mathrm{AP}, \mathrm{BL}, \mathrm{CT}$, and $\mathrm{R} \sqcup$ contributed to the design of the study, data acquisition and interpretation, and manuscript revision. $\mathrm{AB}$ and $\mathrm{SS}$ contributed to the neuroimaging data processing, interpretation, and manuscript revision. VDLS is the main MD investigator, he supervised the recruitment of the patients, and participated in the study design and data interpretation. BD, DV, and GP participated in study design, data interpretation, and/or manuscript revision. GC is the principal investigator of IMAP and she supervised the study, the interpretation of data, and the writing of the manuscript. All authors read and approved the final manuscript.

\section{Funding}

The study was supported by Fondation Plan Alzheimer (Alzheimer Plan 2008-2012), Programme Hospitalier de Recherche Clinique (PHRCN 2011 A01493-38 and PHRCN 2012 12-006-0347), Agence Nationale de la Recherche (LONGVIE 2007), Région Basse-Normandie, Association France Alzheimer et maladies apparentées AAP 2013, the Institut National de la Santé et de la Recherche Médicale (INSERM), and the University of Caen Normandy. The funding sources were not involved in the study design, data acquisition, data analysis, or article writing.

\section{Availability of data and materials}

The datasets generated and analysed during the current study are not publicly available due to local privacy regulations but are available from the corresponding author on reasonable request.

\section{Ethics approval and consent to participate}

The IMAP study was approved by the regional ethics committee (Comité de Protection des Personnes Nord-Ouest III) and registered with ClinicalTrials. gov (number NCT01638949). All participants gave written informed consent to the study prior to the investigation.

\section{Consent for publication}

Not applicable

\section{Competing interests}

The authors declare that they have no competing interests.

\section{Author details}

${ }^{1}$ Inserm, Inserm UMR-S U1237, GIP Cyceron, Université de Caen-Normandie, Boulevard H. Becquerel, 14000 Caen, France. ${ }^{2}$ Memory and Aging Center, Department of Neurology, University of California, San Francisco, San Francisco, CA, USA. ${ }^{3}$ Normandie Univ, UNICAEN, PSL Recherche Universités, EPHE, INSERM, U1077, CHU de Caen, Neuropsychologie et Imagerie de la Mémoire Humaine, GIP Cyceron, 14000 Caen, France. ${ }^{4} \mathrm{CHU}$ de Caen, Service de Neurologie, Caen, France. ${ }^{5}$ Department of Clinical Research, Caen Normandy Hospital (CHU) de Caen, 14000 Caen, France.

Received: 20 December 2018 Accepted: 13 June 2019 Published online: 08 July 2019

\section{References}

1. Jessen $F$, Amariglio RE, van Boxtel M, Breteler M, Ceccaldi M, Chételat $G$, et al. A conceptual framework for research on subjective cognitive decline in preclinical Alzheimer's disease. Alzheimers Dement. 2014;10:844-52. https:// doi.org/10.1016/j.jalz.2014.01.001.

2. Reisberg B, Ferris SH, De L, Crook T. The global deterioration scale for assessment of primary degenerative dementia. Am J Psychiatry. 1982;139:1136-9.

3. Sperling RA, Aisen PS, Beckett $L A$, Bennett DA, Craft S, Fagan AM, et al. Toward defining the preclinical stages of Alzheimer's disease: recommendations from the National Institute on Aging-Alzheimer's Association workgroups on diagnostic guidelines for Alzheimer's disease. Alzheimers Dement. 2011;7:280-92. https://doi.org/10.1016/j.jalz.2011.03.003.

4. Dubois $B$, Hampel H, Feldman HH, Scheltens $P$, Aisen $P$, Andrieu $S$, et al. Preclinical Alzheimer's disease: definition, natural history, and diagnostic 
criteria. Alzheimers Dement. 2016;12:292-323. https://doi.org/10.1016/j.jalz. 2016.02.002.

5. Scheef L, Spottke A, Daerr M, Joe A, Striepens N, Kölsch H, et al. Glucose metabolism, gray matter structure, and memory decline in subjective memory impairment. Neurology. 2012;79:1332-9.

6. Stewart R, Dufouil C, Godin O, Ritchie K, Maillard P, Delcroix N, et al. Neuroimaging correlates of subjective memory deficits in a community population. Neurology. 2008;70:1601-7. https://doi.org/10.1212/01.wnl. 0000310982.99438 .54$.

7. Van Der Flier W, Van Buchem M, Weverling-Rijnsburger AWE, Mutsaers ER, Bollen ELEM, Admiraal-Behloul F, et al. Memory complaints in patients with normal cognition are associated with smaller hippocampal volumes. J Neurol. 2004;251:671-5.

8. Perrotin A, de Flores R, Lamberton F, Poisnel G, La Joie R, de la Sayette V, et al. Hippocampal subfield volumetry and $3 \mathrm{D}$ surface mapping in subjective cognitive decline. J Alzheimers Dis. 2015;48:S141-50. https://doi.org/10. 3233/JAD-150087.

9. Striepens N, Scheef L, Wind A, Popp J, Spottke A, Cooper-Mahkorn D, et al. Volume loss of the medial temporal lobe structures in subjective memory impairment. Dement Geriatr Cogn Disord. 2010;29:75-81. https://doi.org/10. $1159 / 000264630$

10. Hafkemeijer A, Altmann-Schneider I, Oleksik AM, van de Wiel L, Middelkoop HAM, van Buchem MA, et al. Increased functional connectivity and brain atrophy in elderly with subjective memory complaints. Brain Connect. 2013; 3:353-62. https://doi.org/10.1089/brain.2013.0144.

11. Jessen F, Feyen L, Freymann K, Tepest R, Maier W, Heun R, et al. Volume reduction of the entorhinal cortex in subjective memory impairment. Neurobiol Aging. 2006;27:1751-6.

12. Peter J, Scheef L, Abdulkadir A, Boecker H, Heneka M, Wagner M, et al. Gray matter atrophy pattern in elderly with subjective memory impairment. Alzheimers Dement J Alzheimers Assoc. 2014;10:99-108.

13. Schultz SA, Oh JM, Koscik RL, Dowling NM, Gallagher CL, Carlsson CM, et al. Subjective memory complaints, cortical thinning, and cognitive dysfunction in middle-age adults at risk of AD. Alzheimers Dement Diagn Assess Dis Monit. 2015;1:33-40. https://doi.org/10.1016/j.dadm.2014.11.010.

14. Saykin AJ, Wishart HA, Rabin LA, Santulli RB, Flashman LA, West JD, et al. Older adults with cognitive complaints show brain atrophy similar to that of amnestic MCl. Neurology. 2006;67:834-42. https://doi.org/10.1212/01.wnl. 0000234032.77541.a2.

15. van Norden AGW, Fick WF, de Laat KF, van Uden IWM, van Oudheusden LB, Tendolkar I, et al. Subjective cognitive failures and hippocampal volume in elderly with white matter lesions. Neurology. 2008;71:1152-9.

16. Kim M-J, Seo SW, Kim GH, Kim ST, Lee J-M, Qiu A, et al. Less depressive symptoms are associated with smaller hippocampus in subjective memory impairment. Arch Gerontol Geriatr. 2013;57:110-5. https://doi.org/10.1016/j. archger.2013.01.005.

17. Cantero JL, Iglesias JE, Van Leemput K, Atienza M. Regional hippocampal atrophy and higher levels of plasma amyloid-beta are associated with subjective memory complaints in nondemented elderly subjects. J Gerontol Ser A. 2016;71:1210-5. https://doi.org/10.1093/gerona/glw022.

18. Amariglio RE, Mormino EC, Pietras AC, Marshall GA, Vannini P, Johnson KA, et al. Subjective cognitive concerns, amyloid- $\beta$, and neurodegeneration in clinically normal elderly. Neurology. 2015;85:56-62. https://doi.org/10.1212/ WNL.0000000000001712.

19. Mosconi L, De Santi S, Brys M, Tsui WH, Pirraglia E, Glodzik-Sobanska $L$, et al. Hypometabolism and altered cerebrospinal fluid markers in normal apolipoprotein E E4 carriers with subjective memory complaints. Biol Psychiatry. 2008;63:609-18. https://doi.org/10.1016/j. biopsych.2007.05.030

20. Amariglio RE, Becker JA, Carmasin J, Wadsworth LP, Lorius N, Sullivan C, et al. Subjective cognitive complaints and amyloid burden in cognitively normal older individuals. Neuropsychologia. 2012;50:2880-6. https://doi.org/ 10.1016/j.neuropsychologia.2012.08.011.

21. Perrotin A, Mormino EC, Madison CM, Hayenga AO, Jagust WJ. Subjective cognition and amyloid deposition imaging: a Pittsburgh compound B positron emission tomography study in normal elderly individuals. Arch Neurol. 2012;69:223-9. https://doi.org/10.1001/archneurol.2011.666.

22. Snitz BE, Lopez OL, McDade E, Becker JT, Cohen AD, Price JC, et al. Amyloid$\beta$ imaging in older adults presenting to a memory clinic with subjective cognitive decline: a pilot study. J Alzheimers Dis. 2015;48:S151-9. https://doi. org/10.3233/JAD-150113.
23. Snitz BE, Weissfeld LA, Cohen AD, Lopez OL, Nebes RD, Aizenstein HJ, et al. Subjective cognitive complaints, personality and brain amyloid-beta in cognitively normal older adults. Am J Geriatr Psychiatry. 2015;23:985-93. https://doi.org/10.1016/j.jagp.2015.01.008.

24. Mielke MM, Wiste HJ, Weigand SD, Knopman DS, Lowe VJ, Roberts RO, et al. Indicators of amyloid burden in a population-based study of cognitively normal elderly. Neurology. 2012;79:1570-7. https://doi.org/10.1212/WNL. ob013e31826e2696.

25. Perrotin A, La Joie R, de La Sayette V, Barré L, Mézenge F, Mutlu J, et al. Subjective cognitive decline in cognitively normal elders from the community or from a memory clinic: differential affective and imaging correlates. Alzheimers Dement. 2017;13:550-60. https://doi.org/10.1016/j.jalz.2016.08.011.

26. Kaup AR, Nettiksimmons J, LeBlanc ES, Yaffe K. Memory complaints and risk of cognitive impairment after nearly 2 decades among older women. Neurology. 2015;85:1852-8. https://doi.org/10.1212/WNL.0000000000002153.

27. Koppara A, Wagner M, Lange C, Ernst A, Wiese B, König H-H, et al. Cognitive performance before and after the onset of subjective cognitive decline in old age. Alzheimers Dement Diagn Assess Dis Monit. 2015;1:194-205. https://doi.org/10.1016/j.dadm.2015.02.005.

28. Jessen F, Wolfsgruber S, Wiese B, Bickel H, Mösch E, Kaduszkiewicz H, et al. AD dementia risk in late $\mathrm{MCl}$, in early $\mathrm{MCl}$, and in subjective memory impairment. Alzheimers Dement. 2014;10:76-83. https://doi.org/10.1016/j.jalz.2012.09.017.

29. Reisberg B, Shulman MB, Torossian C, Leng L, Zhu W. Outcome over seven years of healthy adults with and without subjective cognitive impairment. Alzheimers Dement J Alzheimers Assoc. 2010;6. https://doi.org/10.1016/j.jalz. 2009.10.002.

30. Mitchell AJ, Beaumont H, Ferguson D, Yadegarfar M, Stubbs B. Risk of dementia and mild cognitive impairment in older people with subjective memory complaints: meta-analysis. Acta Psychiatr Scand. 2014;130:439-51. https://doi.org/10.1111/acps.12336.

31. Rönnlund M, Sundström A, Adolfsson R, Nilsson L-G. Subjective memory impairment in older adults predicts future dementia independent of baseline memory performance: evidence from the Betula prospective cohort study. Alzheimers Dement. 2015;11:1385-92. https://doi.org/10.1016/ j.jalz.2014.11.006.

32. Wang L, van Belle G, Crane PK, Kukull WA, Bowen JD, McCormick WC, et al. Subjective memory deterioration and future dementia in people aged 65 and older. J Am Geriatr Soc. 2004:52:2045-51.

33. Jessen F, Wiese B, Bachmann C, Eifflaender-Gorfer S, Haller F, Kölsch H, et al. Prediction of dementia by subjective memory impairment: effects of severity and temporal association with cognitive impairment. Arch Gen Psychiatry. 2010;67:414-22.

34. Nunes T, Fragata I, Ribeiro F, Palma T, Maroco J, Cannas J, et al. The outcome of elderly patients with cognitive complaints but normal neuropsychological tests. J Alzheimers Dis JAD. 2010;19:137-45.

35. Jack CR, Bennett DA, Blennow K, Carrillo MC, Dunn B, Haeberlein SB, et al. NIA-AA Research Framework: toward a biological definition of Alzheimer's disease. Alzheimers Dement J Alzheimers Assoc. 2018;14:535-62.

36. Blackburn DJ, Wakefield S, Shanks MF, Harkness K, Reuber M, Venneri A. Memory difficulties are not always a sign of incipient dementia: a review of the possible causes of loss of memory efficiency. Br Med Bull. 2014;112:7181. https://doi.org/10.1093/bmb/ldu029.

37. Slot RER, Sikkes SAM, Berkhof J, Brodaty H, Buckley R, Cavedo E, et al. Subjective cognitive decline and rates of incident Alzheimer's disease and non-Alzheimer's disease dementia. Alzheimers Dement J Alzheimers Assoc. 2018;0. https://doi.org/10.1016/j.jalz.2018.10.003.

38. Ponds RW, Commissaris KJ, Jolles J. Prevalence and covariates of subjective forgetfulness in a normal population in The Netherlands. Int J Aging Hum Dev. 1997;45:207-21.

39. Comijs HC, Deeg DJH, Dik MG, Twisk JWR, Jonker C. Memory complaints; the association with psycho-affective and health problems and the role of personality characteristics: a 6-year follow-up study. J Affect Disord. 2002;72: 157-65. https://doi.org/10.1016/S0165-0327(01)00453-0.

40. Clarnette RM, Almeida OP, Forstl H, Paton A, Martins RN. Clinical characteristics of individuals with subjective memory loss in Western Australia: results from a cross-sectional survey. Int I Geriatr Psychiatry. 2001;16:168-74.

41. Kang S-H, Yoon I-Y, Lee SD, Kim T, Lee CS, Han JW, et al. Subjective memory complaints in an elderly population with poor sleep quality. Aging Ment Health. 2017;21:532-6.

42. Gamaldo AA, Wright RS, Aiken-Morgan AT, Allaire JC, Thorpe RJ, Whitfield $\mathrm{KE}$. The association between subjective memory complaints and sleep 
within older African American adults. J Gerontol Ser B. 2019;74:202-11. https://doi.org/10.1093/geronb/gbx069.

43. Lauriola M, Esposito R, Pizzi SD, de Zambotti M, Londrillo F, Kramer JH, et al. Sleep changes without medial temporal lobe or brain cortical changes in community-dwelling individuals with subjective cognitive decline. Alzheimers Dement J Alzheimers Assoc. 2017;13:783-91. https://doi.org/10. 1016/j.jalz.2016.11.006

44. Paradise MB, Glozier NS, Naismith SL, Davenport TA, Hickie IB. Subjective memory complaints, vascular risk factors and psychological distress in the middle-aged: a cross-sectional study. BMC Psychiatry. 2011;11:108.

45. Molinuevo JL, Rabin LA, Amariglio R, Buckley R, Dubois B, Ellis KA, et al. Implementation of subjective cognitive decline criteria in research studies. Alzheimers Dement J Alzheimers Assoc. 2017;13:296-311. https://doi.org/10. 1016/j.jalz.2016.09.012.

46. Rabin LA, Smart CM, Amariglio RE. Subjective cognitive decline in preclinical Alzheimer's disease. Annu Rev Clin Psychol. 2017;13:369-96

47. Rodríguez-Gómez O, Abdelnour C, Jessen F, Valero S, Boada M. Influence of sampling and recruitment methods in studies of subjective cognitive decline. J Alzheimers Dis. 2015;48:S99-107. https://doi.org/10.3233/JAD-150189.

48. Archer HA, Newson MA, Coulthard EJ. Subjective memory complaints: symptoms and outcome in different research settings. J Alzheimers Dis. 2015;48:S109-14. https://doi.org/10.3233/JAD-150108.

49. Amariglio RE, Donohue MC, Marshall GA, Rentz DM, Salmon DP, Ferris SH, et al. Tracking early decline in cognitive function in older individuals at risk for Alzheimer's disease dementia: the Alzheimer's Disease Cooperative Study Cognitive Function Instrument. JAMA Neurol. 2015;72:446-54. https://doi. org/10.1001/jamaneurol.2014.3375.

50. Caselli RJ, Chen K, Locke DEC, Lee W, Roontiva A, Bandy D, et al. Subjective cognitive decline: self and informant comparisons. Alzheimers Dement $J$ Alzheimers Assoc. 2014;10:93-8.

51. Wilson RS, Begeny CT, Boyle PA, Schneider JA, Bennett DA. Vulnerability to stress, anxiety, and development of dementia in old age. Am J Geriatr Psychiatry. 2011;19:327-34. https://doi.org/10.1097/JGP.0b013e31820119da.

52. Pietrzak RH, Lim YY, Neumeister A, Ames D, Ellis KA, Harrington $K$, et al. Amyloid- $\beta$, anxiety, and cognitive decline in preclinical Alzheimer disease: a multicenter, prospective cohort study. JAMA Psychiatry. 2015;72:284-91. https://doi.org/10.1001/jamapsychiatry.2014.2476.

53. Yochim BP, Mueller AE, Segal DL. Late life anxiety is associated with decreased memory and executive functioning in community dwelling older adults. J Anxiety Disord. 2013;27:567-75.

54. Kaup AR, Byers AL, Falvey C, Simonsick EM, Satterfield S, Ayonayon HN, et al. Trajectories of depressive symptoms in older adults and risk of dementia. JAMA Psychiatry. 2016;73:525-31. https://doi.org/10.1001/jamapsychiatry.2016.0004.

55. Donovan NJ, Hsu DC, Dagley AS, Schultz AP, Amariglio RE, Mormino EC, et al. Depressive symptoms and biomarkers of Alzheimer's disease in cognitively normal older adults. J Alzheimers Dis JAD. 2015;46:63-73.

56. La Joie R, Perrotin A, Egret S, Pasquier F, Tomadesso C, Mézenge F, et al. Qualitative and quantitative assessment of self-reported cognitive difficulties in nondemented elders: association with medical help seeking, cognitive deficits, and $\beta$-amyloid imaging. Alzheimers Dement Diagn Assess Dis Monit. 2016;5:23-34. https://doi.org/10.1016/j.dadm.2016.12.005.

57. La Joie R, Perrotin A, Barré L, Hommet C, Mézenge F, Ibazizene $M$, et al. Region-specific hierarchy between atrophy, hypometabolism, and $\beta$-amyloid (Aß) load in Alzheimer's disease dementia. J Neurosci. 2012;32:16265-73. https://doi.org/10.1523/JNEUROSCI.2170-12.2012

58. Anterion CT, Ribas C, Honoré-Masson S, Berne G, Ruel JH, Laurent B. Le questionnaire de plainte cognitive (QPC): un outil de recherche de plainte suspecte d'évoquer une maladie d'Alzheimer? [Cognitive Complaint Questionnaire. L'Année Gérontologique. 2003. p. 56-65. http://www.bdsp. ehesp.fr/Base/277296/.

59. McNair D, Kahn R. Self-assessment of cognitive deficits. Assessment in geriatric psychopharmacology 119-36. Assessment in geriatric psychopharmacology; 1983.

60. Montgomery SA, Asberg M. A new depression scale designed to be sensitive to change. Br J Psychiatry J Ment Sci. 1979;134:382-9.

61. Spielberger CD, Gorsuch RL, Lushene RE. Manual for the state-trait anxiety inventory. 1970. https://ubir.buffalo.edu/xmlui/handle/10477/2895. Accessed 28 Sept 2018.

62. Folstein MF, Folstein SE, McHugh PR. "Mini-mental state": a practical method for grading the cognitive state of patients for the clinician. J Psychiatr Res. 1975;12:189-98. https://doi.org/10.1016/0022-3956(75)90026-6.
63. Mattis S. Mental status examination for organic mental syndrome in the elderly patients. In: Geriatric psychiatry: a handbook for psychiatrists and primary care physicians; 1976. p. 77-121.

64. Eustache $F$, Laisney $M$, Lalevée $C$, Pèlerin A, Perrotin A, Egret $\mathrm{S}$, et al. Une nouvelle épreuve de mémoire épisodique : l'épreuve ESR-forme réduite (ESR-r), adaptée du paradigme ESR (encodage, stockage, récupération), A new episodic memory task: the short-ESR (s-ESR) task adapted from the Encoding Storage Retrieval paradigm. Rev Neuropsychol. 2015;7:217-25. https://doi.org/10.1684/nrp.2015.0351.

65. Boccardi M, Laakso MP, Bresciani L, Galluzzi S, Geroldi C, Beltramello A, et al. The MRI pattern of frontal and temporal brain atrophy in fronto-temporal dementia. Neurobiol Aging. 2003;24:95-103.

66. Chételat G, Eustache F, Viader F, De La Sayette V, Pélerin A, Mézenge F, et al. FDG-PET measurement is more accurate than neuropsychological assessments to predict global cognitive deterioration in patients with mild cognitive impairment. Neurocase. 2005;11:14-25.

67. Villain N, Desgranges B, Viader F, de la SV, Mézenge F, Landeau B, et al. Relationships between hippocampal atrophy, white matter disruption, and gray matter hypometabolism in Alzheimer's disease. J Neurosci. 2008;28: 6174-81. https://doi.org/10.1523/JNEUROSCI.1392-08.2008.

68. Chételat $G$, Desgranges $B$, Landeau B, Mézenge F, Poline JB, de la Sayette $V$, et al. Direct voxel-based comparison between grey matter hypometabolism and atrophy in Alzheimer's disease. Brain J Neurol. 2008:131(Pt 1):60-71.

69. Bejanin A, La Joie R, Landeau B, Belliard S, de La Sayette V, Eustache F, et al. Distinct interplay between atrophy and hypometabolism in Alzheimer's versus semantic dementia. Cereb Cortex. 2019;29:1889-99. https://doi:10 1093/cercor/bhy069

70. Besson FL, Joie RL, Doeuvre L, Gaubert M, Mézenge F, Egret S, et al. Cognitive and brain profiles associated with current neuroimaging biomarkers of preclinical Alzheimer's disease. J Neurosci. 2015;35:10402-11. https://doi.org/10.1523/JNEUROSCI.0150-15.2015.

71. Mutlu J, Landeau B, Gaubert M, de La Sayette V, Desgranges B, Chételat G. Distinct influence of specific versus global connectivity on the different Alzheimer's disease biomarkers. Brain J Neurol. 2017;140:3317-28.

72. Ramakers $I H G B$, Visser PJ, Bittermann AJN, Ponds RWHM, van Boxtel MPJ, Verhey FRJ. Characteristics of help-seeking behaviour in subjects with subjective memory complaints at a memory clinic: a case-control study. Int J Geriatr Psychiatry. 2009;24:190-6.

73. Jorm AF, Butterworth P, Anstey KJ, Christensen H, Easteal S, Maller J, et al. Memory complaints in a community sample aged 60-64 years: associations with cognitive functioning, psychiatric symptoms, medical conditions, APOE genotype, hippocampus and amygdala volumes, and white-matter hyperintensities. Psychol Med. 2004;34:1495-506.

74. Begum A, Whitley R, Banerjee S, Matthews D, Stewart R, Morgan C. Helpseeking response to subjective memory complaints in older adults: toward a conceptual model. The Gerontologist. 2013;53:462-73.

75. Hurt CS, Burns A, Brown RG, Barrowclough C. Why don't older adults with subjective memory complaints seek help? Int J Geriatr Psychiatry. 2012;27:394-400.

76. Werner P. Beliefs about memory problems and help seeking in elderly persons. Clin Gerontol. 2004;27:19-30.

77. da Silva RAPC. Sleep disturbances and mild cognitive impairment: a review. Sleep Sci. 2015;8:36-41. https://doi.org/10.1016/j.slsci.2015.02.001.

78. Hita-Yañez E, Atienza M, Cantero JL. Polysomnographic and subjective sleep markers of mild cognitive impairment. Sleep. 2013;36:1327-34.

79. Buckley R, Saling MM, Ames D, Rowe CC, Lautenschlager NT, Macaulay SL, et al. Factors affecting subjective memory complaints in the AIBL aging study: biomarkers, memory, affect, and age. Int Psychogeriatr. 2013;25:130715. https://doi.org/10.1017/S1041610213000665.

80. Hollands S, Lim YY, Buckley R, Pietrzak RH, Snyder PJ, Ames D, et al. Amyloid- $\beta$ related memory decline is not associated with subjective or informant rated cognitive impairment in healthy adults. J Alzheimers Dis. 2015;43:677-86

81. Zwan MD, Villemagne $V L$, Doré $V$, Buckley $R$, Bourgeat $P$, Veljanoski $R$, et al. Subjective memory complaints in APOE $\varepsilon 4$ carriers are associated with high amyloid- $\beta$ burden. J Alzheimers Dis. 2016;49:1115-22. https://doi.org/10. 3233/JAD-150446.

82. Rowe CC, Ellis KA, Rimajova M, Bourgeat P, Pike KE, Jones $G$, et al. Amyloid imaging results from the Australian Imaging, Biomarkers and Lifestyle (AIBL) study of aging. Neurobiol Aging. 2010;31:1275-83. https://doi.org/10.1016/j. neurobiolaging.2010.04.007. 
83. Pini L, Pievani M, Bocchetta M, Altomare D, Bosco P, Cavedo E, et al. Brain atrophy in Alzheimer's disease and aging. Ageing Res Rev. 2016;30:25-48. https://doi.org/10.1016/j.arr.2016.01.002.

84. Chételat G, Mézenge F, Tomadesso C, Landeau B, Arenaza-Urquijo E, Rauchs $G$, et al. Reduced age-associated brain changes in expert meditators: a multimodal neuroimaging pilot study. Sci Rep. 2017;7. https://doi.org/10. 1038/s41598-017-07764-x.

85. Fjell AM, Walhovd KB. Structural brain changes in aging: courses, causes and cognitive consequences. Rev Neurosci. 2010;21:187-221.

86. Kalpouzos G, Chételat G, Baron J-C, Landeau B, Mevel K, Godeau C, et al. Voxel-based mapping of brain gray matter volume and glucose metabolism profiles in normal aging. Neurobiol Aging. 2009;30:112-24.

87. Spampinato MV, Wood JN, De Simone V, Grafman J. Neural correlates of anxiety in healthy volunteers: a voxel-based morphometry study. J Neuropsychiatry Clin Neurosci. 2009;21:199-205.

88. Du M-Y, Wu Q-Z, Yue Q, Li J, Liao Y, Kuang W-H, et al. Voxelwise metaanalysis of gray matter reduction in major depressive disorder. Prog NeuroPsychopharmacol Biol Psychiatry. 2012;36:11-6. https://doi.org/10.1016/j. pnpbp.2011.09.014.

89. Aljondi R, Szoeke C, Steward C, Yates P, Desmond P. A decade of changes in brain volume and cognition. Brain Imaging Behav. 2018. https://doi.org/ 10.1007/s11682-018-9887-z.

90. den Heijer T, van der Lijn F, Koudstaal PJ, Hofman A, van der Lugt A, Krestin $\mathrm{GP}$, et al. A 10-year follow-up of hippocampal volume on magnetic resonance imaging in early dementia and cognitive decline. Brain J Neurol. 2010;133(Pt 4):1163-72.

91. Weiner MW, Veitch DP, Aisen PS, Beckett LA, Cairns NJ, Cedarbaum J, et al. 2014 update of the Alzheimer's Disease Neuroimaging Initiative: a review of papers published since its inception. Alzheimers Dement J Alzheimers Assoc. 2015;11:e1-120. https://doi.org/10.1016/j.jalz.2014.11.001.

92. Gifford KA, Liu D, Lu Z, Tripodis Y, Cantwell NG, Palmisano J, et al. The source of cognitive complaints predicts diagnostic conversion differentially among nondemented older adults. Alzheimers Dement. 2014;10:319-27. https://doi.org/10.1016/j.jalz.2013.02.007.

93. Balash Y, Mordechovich M, Shabtai H, Giladi N, Gurevich T, Korczyn AD. Subjective memory complaints in elders: depression, anxiety, or cognitive decline? Acta Neurol Scand. 2013;127:344-50. https://doi.org/10.1111/ane.12038.

94. Bierman EJM, Comijs HC, Jonker C, Beekman ATF. Symptoms of anxiety and depression in the course of cognitive decline. Dement Geriatr Cogn Disord. 2007;24:213-9. https://doi.org/10.1159/000107083.

95. Innes KE, Selfe TK. Meditation as a therapeutic intervention for adults at risk for Alzheimer's disease - potential benefits and underlying mechanisms. Front Psychiatry. 2014;5. https://doi.org/10.3389/fpsyt.2014.00040.

96. Aisen PS, Petersen RC, Donohue MC, Gamst A, Raman R, Thomas RG, et al. Clinical core of the Alzheimer's disease neuroimaging initiative: progress and plans. Alzheimers Dement. 2010;6:239-46. https://doi.org/10.1016/j.jalz. 2010.03.006

Ready to submit your research? Choose BMC and benefit from:

- fast, convenient online submission

- thorough peer review by experienced researchers in your field

- rapid publication on acceptance

- support for research data, including large and complex data types

- gold Open Access which fosters wider collaboration and increased citations

- maximum visibility for your research: over $100 \mathrm{M}$ website views per year

At BMC, research is always in progress.

Learn more biomedcentral.com/submissions 